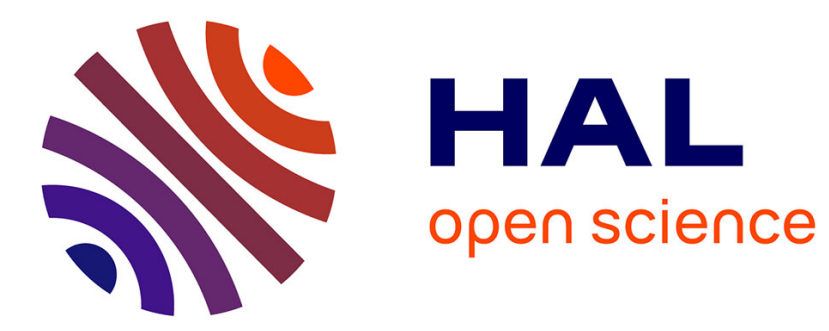

\title{
Photoinduced Aerobic Iodoarene-Catalyzed Spirocyclization of N-Oxy-Amides to N-Fused Spirolactams
}

\author{
Loïc Habert, Kevin Cariou
}

\section{- To cite this version:}

Loïc Habert, Kevin Cariou. Photoinduced Aerobic Iodoarene-Catalyzed Spirocyclization of N-OxyAmides to N-Fused Spirolactams. Angewandte Chemie International Edition, 2021, 60 (1), pp.171-175. 10.1002/anie.202009175 . hal-03367856

\section{HAL Id: hal-03367856 https://hal.science/hal-03367856}

Submitted on 6 Oct 2021

HAL is a multi-disciplinary open access archive for the deposit and dissemination of scientific research documents, whether they are published or not. The documents may come from teaching and research institutions in France or abroad, or from public or private research centers.
L'archive ouverte pluridisciplinaire HAL, est destinée au dépôt et à la diffusion de documents scientifiques de niveau recherche, publiés ou non, émanant des établissements d'enseignement et de recherche français ou étrangers, des laboratoires publics ou privés. 


\title{
Photoinduced Aerobic lodoarene-Catalyzed Spirocyclization of $\mathbf{N}$ - Oxy-Amides to $\mathbf{N}$-Fused Spirolactams
}

\author{
Loïc Habert, ${ }^{[a],[b]}$ Kevin Cariou ${ }^{[a],[b] *}$
}

In memory of Professor Kilian Muñiz (1970-2020)

\author{
[a] Institut de Chimie des Substances Naturelles, LabEx LERMIT, UPR 2301 \\ Université Paris-Saclay, CNRS \\ 1, avenue de la Terrasse, 91198, Gif-sur-Yvette, France \\ [b] Current address: Institute of Chemistry for Life and Health Sciences, Laboratory for Inorganic Chemical Biology \\ Chimie ParisTech, PSL University, CNRS \\ 11, rue Pierre et Marie Curie 75005 Paris, France \\ E-mail: kevin.cariou@cnrs.fr \\ Supporting information for this article is given via a link at the end of the document.
}

\begin{abstract}
: lodoarene catalysis is a powerful methodology that usually requires an excess of oxidant, or of redox mediator if the terminal oxidant is dioxygen, to generate the key hypervalent iodine intermediate to proceed efficiently. We report that, using the spirocyclization of amides as a benchmark reaction, aerobic iodoarene catalysis can be enabled by relying on a pyrylium photocatalyst under blue light irradiation. This unprecedented dual organocatalytic system allows the use of low catalytic loading of both catalysts under very mild operating conditions.
\end{abstract}

Hypervalent iodine(III) compounds have been known for 130 years, ${ }^{[1]}$ yet interest in their reactivity was very modest until the 80 's, before witnessing a dramatic surge in the 2000's. ${ }^{[2-4]}$ They possess many advantages in terms of versatility, high selectivity and lack of toxicity; however, their use as a stoichiometric reagent remains a drawback. Indeed, the driving force behind their reactivity is the final release of one equivalent of iodoarene (Scheme 1a), such as iodobenzene. The liberation of a stoichiometric amount of organic waste is in total contradiction with the need for greener and more responsible processes. In order to circumvent these hurdles, the more general and sought after strategy is based on the in situ re-oxidation of the iodoarene into a reactive iodine(III) species. This approach, pioneered by Ochiai \& Miyamoto ${ }^{[5]}$ and by Kita ${ }^{[6]}$ in 2005 , de facto establishes iodoarenes as a particular subclass of organocatalysts, ${ }^{[7-9]}$ with many synthetic applications, including asymmetric versions. ${ }^{[10,11]}$

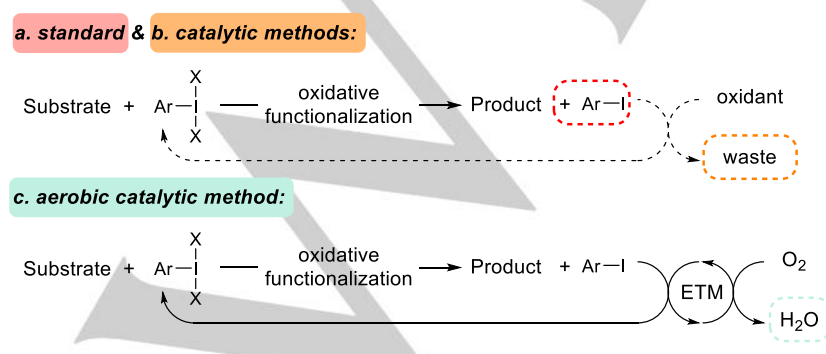

Scheme 1. Stoichiometric iodoarene oxidative transformation (a), iodoarene catalysis (b) and aerobic iodoarene catalysis (c).
Apart from anodic oxidation, which, more than 20 years after the pioneering studies by Fujita, ${ }^{[12]}$ currently receives increasing attention, ${ }^{[13-19]}$ iodoarene catalysis requires the use of a stoichiometric oxidant, ${ }^{[8]}$ thus generating an equimolar quantity of inorganic or organic waste (Scheme 1b). A more desirable alternative is the use of molecular oxygen as a widely available and cheap stoichiometric oxidant that would only generate aqueous waste (Scheme 1c). Since the single electron oxidation potential of iodobenzene is much higher (half peak potential: $E_{p / 2}$ $=2.17 \mathrm{~V}$ vs SCE $)^{[20]}$ than the reduction potential of oxygen $(-0.33$ $\mathrm{V}$ vs SHE, for single electron reduction at $\mathrm{pH}=7),{ }^{[21]}$ resorting to an electron-transfer mediator ${ }^{[22]}$ (ETM) is mandatory. This strategy was eventually implemented in 2017 by Miyamoto \& Uchiyama $^{[23]}$ and Powers ${ }^{[24]}$ who independently reported the first examples of aerobic oxidation of iodoarenes. Both approaches are based on the formation of a suitable oxidant during the $\mathrm{O}_{2}$ mediated autoxidation of aldehydes, ${ }^{[25-27]}$ although the protocols slightly differ. The Miyamoto-Uchiyama protocol requires a sterically hindered aldehyde and was applied to the glycol scission of 1,2-diols and the Hofmann rearrangement of primary amides with only 3 to 5 equivalents of iso-butyraldehyde and 5 to 20 mol\% of pentamethyliodobenzene. ${ }^{[23]}$ Powers' method, which was further refined for the formation of iodine $(\mathrm{V})$ reagents, ${ }^{[28]}$ uses 10 equivalents of acetaldehyde and $1 \mathrm{~mol} \%$ of $\mathrm{CoCl}_{2}$ as the initiator to promote the synthesis of (diacetoxy)iodoarenes from the corresponding aryl iodides in acetic acid. This system was named "oxidase catalysis" by the authors. ${ }^{[29]}$ Five distinct examples of catalytic applications were presented, necessitating between 10 to $20 \mathrm{~mol} \%$ of diiodobenzene and one equivalent of iodobenzene to work efficiently. Despite the spectacular improvement that these aerobic strategies bring to iodoarene catalysis, yet they still require a rather large excess of aldehyde and, in some cases, even a stoichiometric amount of the iodobenzene catalyst.

With the goal of developing an aerobic system that would only require a substoichiometric amount of the $\mathrm{O}_{2}$-mediator we sought to employ a visible-light photoredox catalyst to reoxidize the iodoarene into an iodine(III) derivative. Since the 2011 study by Lalevée on the use of a ruthenium photocatalyst with a diphenyliodonium to form phenyl radicals, ${ }^{[30]}$ the interplay 
between visible-light photoredox catalysis and hypervalent iodine(III) derivatives has been increasingly studied. ${ }^{[31]}$ However, all these studies rely on the reduction of iodine(III) reagents to give an aryliodide by-product while there is no report of a photoredox oxidation of an iodoarene into an iodine(III) derivative. The oxidation potential of aryliodides being quite high, ${ }^{[20]}$ it precludes the use of most Ru- and Ir-based complexes ${ }^{[32]}$ in favor of organic dyes ${ }^{[33-35]}$ such as acridinium (Fukuzumi's catalyst $\mathrm{Acr}^{+}$) or pyrylium (pyry ${ }^{+}$) salts.

To explore this dual (iodoarene/photocatalyst) catalytic system, the spirocyclization of amides into $\mathrm{N}$-fused spirolactams was chosen as a benchmark reaction. After their initial work on the generation of nitrenium ions from chloramides, ${ }^{[36]}$ this transformation was then developed by Kikugawa in 2003 using a stoichiometric amount bis(trifluoroacetoxy)iodo]benzene (PIFA) in trifluoroethanol (TFE) (Scheme 2a). ${ }^{[37]}$ This reaction was later reported using anodically generated iodine(III) by Nishiyama. ${ }^{[38]}$ In 2007, Kita described a catalytic version, using $10 \mathrm{~mol} \%$ of iodotoluene in the presence of 1.5 equivalents of m-CPBA (Scheme $2 b)^{[39]}$ while Togo used Oxone. ${ }^{[40]}$ Kita later refined this method using 2 mol\% of a diiodobiaryl with 2 equivalents of peracetic acid. ${ }^{[41]}$ Finally, this reaction was one of the examples that Powers ${ }^{[24]}$ implemented in an aerobic fashion with $20 \mathrm{~mol} \%$ of diiiodobenzene and 10 equivalents of acetaldehyde (Scheme 2c). For our part, we set to establish the feasibility of this transformation under aerobic conditions with an iodoarene catalyst, which would be oxidized using an organic photocatalyst $\left(\right.$ phot $^{+}$) under irradiation (Scheme 2d).

The reaction was first studied with $N$-Methoxy amide $1 \mathrm{a}$ as the starting material using a high catalyst loading of iodobenzene (50 mol\%) in the presence of $2.5 \mathrm{~mol} \%$ of 2,4,6-triphenylpyrylium tetrafluoroborate $\left(\mathrm{TPT}, \mathrm{E}_{1 / 2} \mathrm{P}^{*} / \mathrm{P} \cdot=2.30 \mathrm{~V} \text { vs. } \mathrm{SCE}\right)^{[42]}$ as the photocatalyst, under one atmosphere of dioxygen and irradiation at $455 \mathrm{~nm}$ (Table 1). The influence of the solvent was dramatic as no reaction was observed in dichloroethane (DCE) or acetonitrile, while trifluoroethanol (TFE) and hexafluoroisopropanol (HFIP) enabled the formation of the desired spiro-adduct in $10 \%$ and $18 \%$, respectively. Doubling or tripling the reaction time allowed to double the yield to $37 \%$. As the TPT catalyst is known for its poor photo-stability, we used the more robust and more oxidizing mesityl-2,6-diphenylpyrylium tetrafluoroborate (MDPT, $\mathrm{E}_{1 / 2} \mathrm{P}^{*} / \mathrm{P}$. $=2.62 \mathrm{~V}$ vs. SCE) recently developed by Beeler. ${ }^{[43]}$ This led to a slight improvement of the yield to $43 \%$. On the contrary, the use of 9-mesityl-10-phenylacridinium tetrafluoroborate (Ph-Acr, $\mathrm{E}_{1 / 2}$ $\mathrm{P}^{*} / \mathrm{P} \cdot=2.20 \mathrm{~V}$ vs. SCE $)^{[44]}$ did not permit the reaction to proceed.

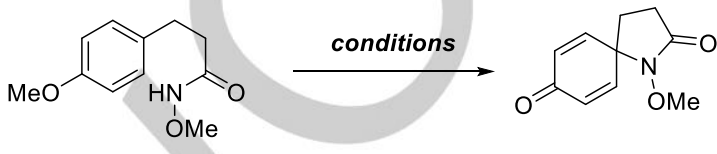

a. Kikugawa, 2003, stoichiometric

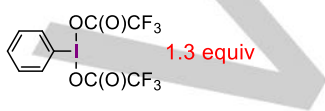

TFE, $65^{\circ} \mathrm{C}, 10 \mathrm{~min}, 80 \%$

c. Powers, 2018, aerobic catalytic II $20 \mathrm{~mol} \%$

$\mathrm{CH}_{3} \mathrm{CHO}, 10$ equiv

$\mathrm{O}_{2}$ (1 atm.), $\mathrm{CoCl}_{2} \cdot 6 \mathrm{H}_{2} \mathrm{O} 1 \mathrm{~mol} \%$ DCE, $23^{\circ} \mathrm{C}, 16 \mathrm{~h}, 77 \%$

$$
\text { b. Kita, 2007, catalytic }
$$

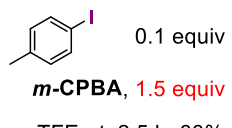

TFE, rt, 2.5 h, $83 \%$

d. this work, aerobic photocatalytic

$$
\mathrm{O}_{2}+\mathrm{S}+\text { phot }^{+} \text {cat. }
$$

Scheme 2. Spirocyclization of amides to $N$-fused spirolactams using a stoichiometric iodine(III) reagent (a), iodoarene catalysis (b), aerobic iodoarene catalysis (c) and dual aerobic photo- and iodoarene catalysis (d, this work).

Table 1. Optimization of the reaction conditions ${ }^{[a]}$

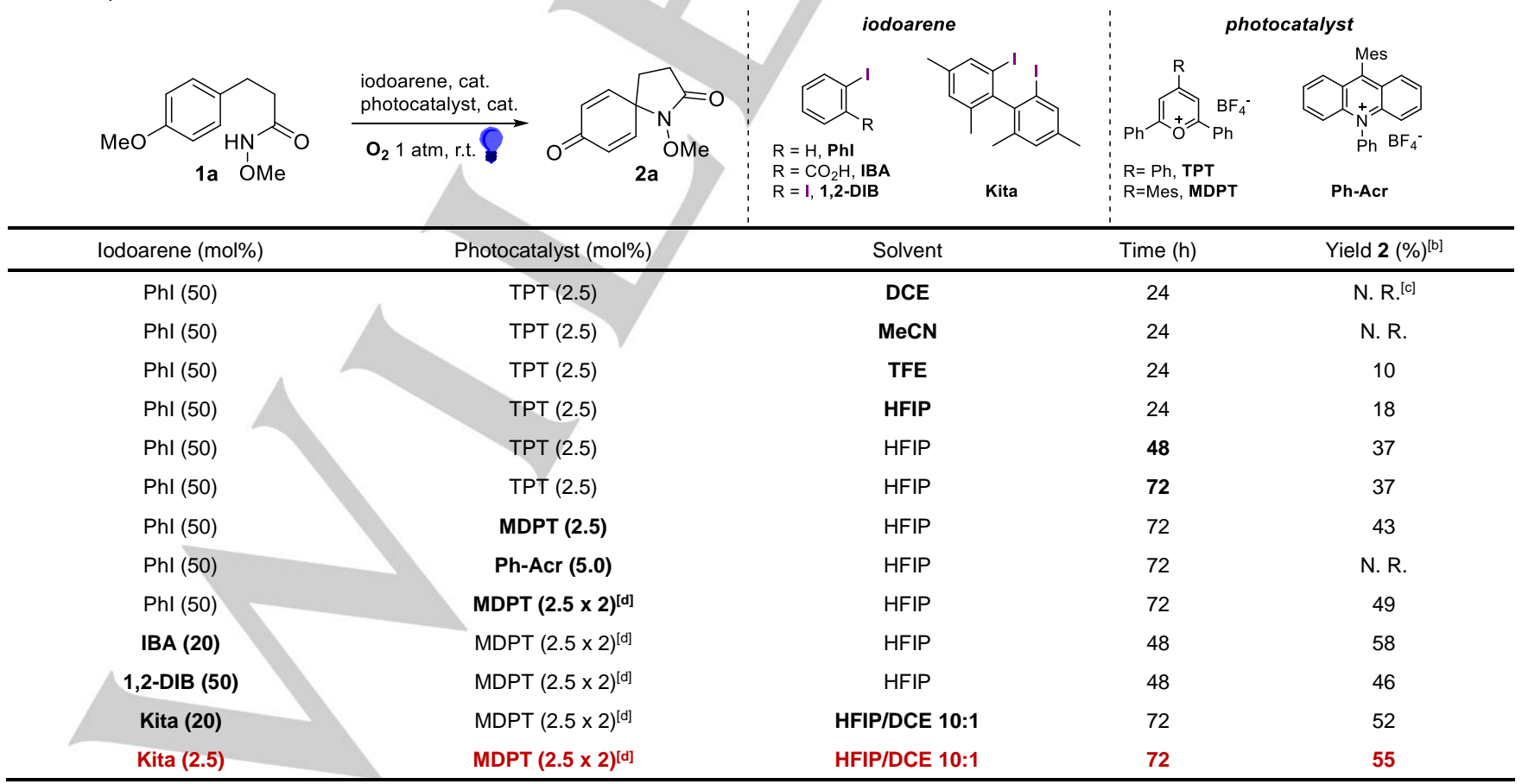

[a] All reactions were carried out with $0.28 \mathrm{mmol}$ of $1 \mathrm{a}$, stirred in $1.5 \mathrm{~mL}$ of solvent under $455 \mathrm{~nm}$ irradiation. [b] isolated yields. [c] no reaction. [d] The reaction was started with $2.5 \mathrm{~mol} \%$ of catalyst, another $2.5 \mathrm{~mol} \%$ was added after half the reaction time. 
To favor the oxidation of the iodoarene, derivatives bearing a substituent in ortho were then assayed. Using $20 \mathrm{~mol} \%$ of iodobenzoic acid (IBA), which could lead to a transient benziodoxole intermediate, ${ }^{[45-47]}$ spiro adduct 2 a could be isolated with a $58 \%$ yield. 1,2-Diiodobenzene, that can form $\mu$-oxo intermediates, ${ }^{[48]}$ was less effective and a $46 \%$ yield was obtained. Finally, Kita's bis iodoarene catalys ${ }^{[41]}$ was employed (DCE was added to HFIP to increase its solubility) and a $55 \%$ yield could be obtained with a catalyst loading of only $2.5 \mathrm{~mol} \%$. Being almost as efficient as with $20 \mathrm{~mol} \%$ of IBA, these conditions were selected as optimal since only $2.5 \mathrm{~mol} \%$ of the iodoarene catalyst and $5 \mathrm{~mol} \%$ of the photocatalyst are needed to promote the spirocyclization.

When the $\mathrm{N}$-methoxy group was changed for an ethoxy, or a benzyloxy group the corresponding spiro-adducts $\mathbf{2 b}$ and $\mathbf{2 c}$ were obtained with $59 \%$ and $63 \%$ yield, respectively (Scheme 3a).While electron-rich groups were not suitable for the reaction (vide infra), electron-poor benzyloxy groups such as pentafluorobenzyl and para-nitrobenzyl groups were compatible and yielded 2d (39\%) and 2 e (51\%). The spirocyclization also proceeded smoothly with various $\mathrm{N}$-acyloxy amides, whether an acetate $(\mathbf{2 f}, 61 \%)$, a pivalate $(\mathbf{2 g}, 52 \%)$, a phenyl acetate $(\mathbf{2} \mathbf{h}$, $53 \%)$, a benzoate $(\mathbf{2} \mathbf{i}, 46 \%)$ or a meta-nitrobenzoate $(\mathbf{2} \mathbf{j}, 47 \%)$.

More diversely substituted $\mathrm{N}$-alkoxy derivatives also underwent the spirocyclization, including the propargyl and allyl derivatives (2k, $46 \%$ and $2 \mathrm{I}, 50 \%)$ and the chloropentanyl compound (2m, $45 \%)$. Yet for several substrates the reaction only led to a complex mixture, although it could not be determined if it was due to a decomposition of the starting material, the final product or both (Scheme $3 b$ ). These included $\mathrm{N}$-oxy derivatives with an electronrich group (1n), a hydroxyl functionality (10), a silyl group (1p) or a tertiary ether (1q). In contrast with what was observed by Kita,

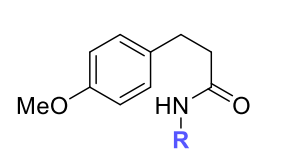

Kita's catalyst, $2.5 \mathrm{~mol} \%$ MDPT, 2 × $2.5 \mathrm{~mol} \%$ $\mathrm{O}_{2}, 1 \mathrm{~atm}, \mathrm{hv}=455 \mathrm{~nm}$ HFIP/DCE 10:1 $33^{\circ} \mathrm{C}, 72 \mathrm{~h}$

a. scope
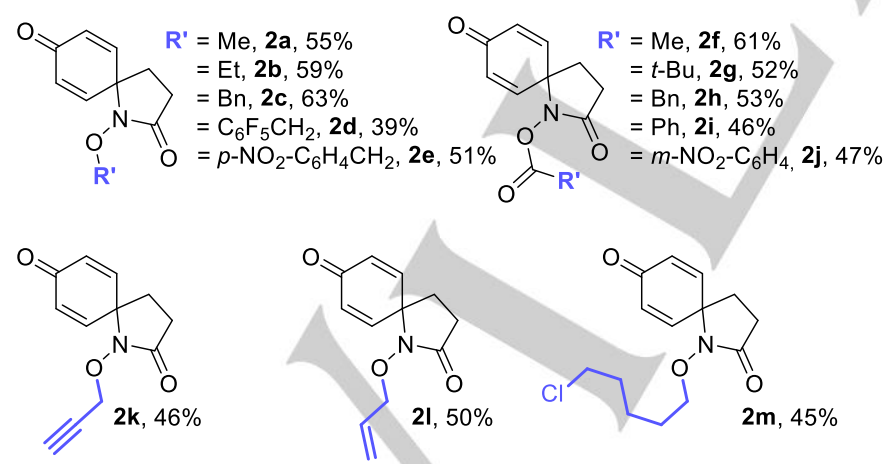

b. subtrates leading to degradation

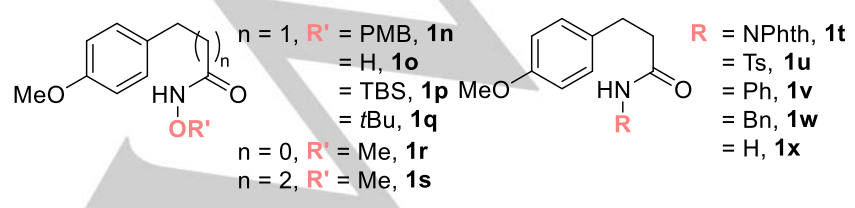

Scheme 3. Scope and limitations of the spirocyclization of amides to $\mathrm{N}$-fused spirolactams under photoinduced aerobic iodoarene catalysis. substrates $1 \mathrm{r}$ and 1s, which would have furnished the 4membered and 6-membered spiro derivatives, respectively, only led to decomposition. Other types of substituent that could help stabilize a putative radical intermediate on the nitrogen such as a phthalimidate $(\mathbf{1 t}){ }^{[39,41]}$ a tosyl $(\mathbf{1 u})$ or a phenyl $(\mathbf{1 v})$ were also ineffective, and so was an alkyl group (1w) or an unprotected amide (1x). Control experiments (Scheme 4) showed that the reaction did no proceed in the absence of either catalyst, oxygen or light, nor in the presence of $20 \mathrm{~mol} \%$ of a radical quench such as BHT and TEMPO. When air was used instead of pure dioxygen, the reaction only yielded $12 \%$ of $2 a$. Finally, acetic acid was used as a highly polar and protic solvent but no reaction took place.

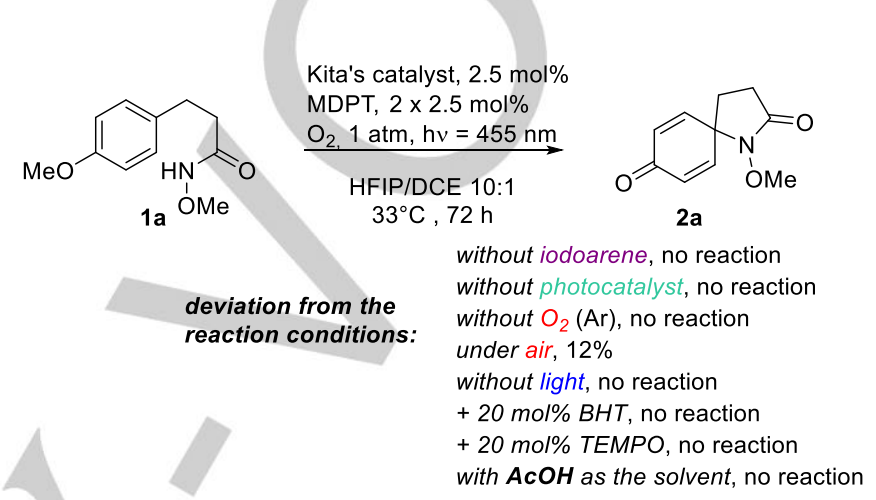

Scheme 4. Control experiments.

These observations led us to propose a plausible mechanism based on a dual organocatalytic system (Scheme 5). Photoexcitation of the pyrylium Pyry $^{+}$would generate the highly oxidizing Pyry $^{+*}\left(E^{*} \text { red VS SCE }=2.62 \mathrm{~V}\right)^{[43]}$ that could promote the oxidation of iodoarene $\mathbf{A}$ into iodoaryl radical cation $\mathbf{B}$ and form Pyry: Oxidation of the latter into Pyry by the dioxygen would close the photoredox catalytic cycle and generate the superoxide ion. ${ }^{49]}$ lodoaryl radical cation $\mathbf{B}$ has been proposed as an intermediate in the anodic generation of iodine(III) reagents ${ }^{[19]}$ and could serve as a precursor to iodanyl radical $\mathbf{C},{ }^{[27]}$ upon reaction with the solvent. After combination with the superoxide and protonation peroxy-iodinane D could be formed. Eventually, full solvolysis could occur leading to iodinane E. ${ }^{[13,14]}$ This spirocyclization has been proposed to occur through the initial formation of a nitrenium ion ${ }^{[39]}$ but a $\mathrm{N}$-centered radical, stabilized by the alkoxy group, ${ }^{[50]}$ could also be operative. This means that all three species $\mathbf{C}, \mathbf{D}$ and $\mathbf{E}$ could promote the transformation of 1 into 2 , by triggering the formation of a reactive nitrogen intermediate. In all cases, this would regenerate the starting iodoarene, thus closing the second catalytic cycle. Control experiments demonstrate that several factors are essential for this dual catalytic system to be operative. As evidenced by the absence of reactivity in non-fluorinated solvent, including the highly polar and protic $\mathrm{AcOH}, \mathrm{HFIP}$ solvent is essential, a feature that has already been noted for electrochemical generation of iodine(III) species, ${ }^{[17-19]}$ presumably via multiple roles. First, its superior solvatation properties for charged species ${ }^{[51]}$ such as arene radical cations generated in photoredox process, ${ }^{[52]}$ would favor the formation of $\mathbf{B}$ and $\mathbf{C}$. Moreover, when apically bound to the iodine in $\lambda^{3}$-iodanes $\mathbf{D}$ or $\mathbf{E}$, its strong electron-withdrawing character would enhance the stabilization of the 3-center 4electron hypervalent bond. ${ }^{[53]}$ 


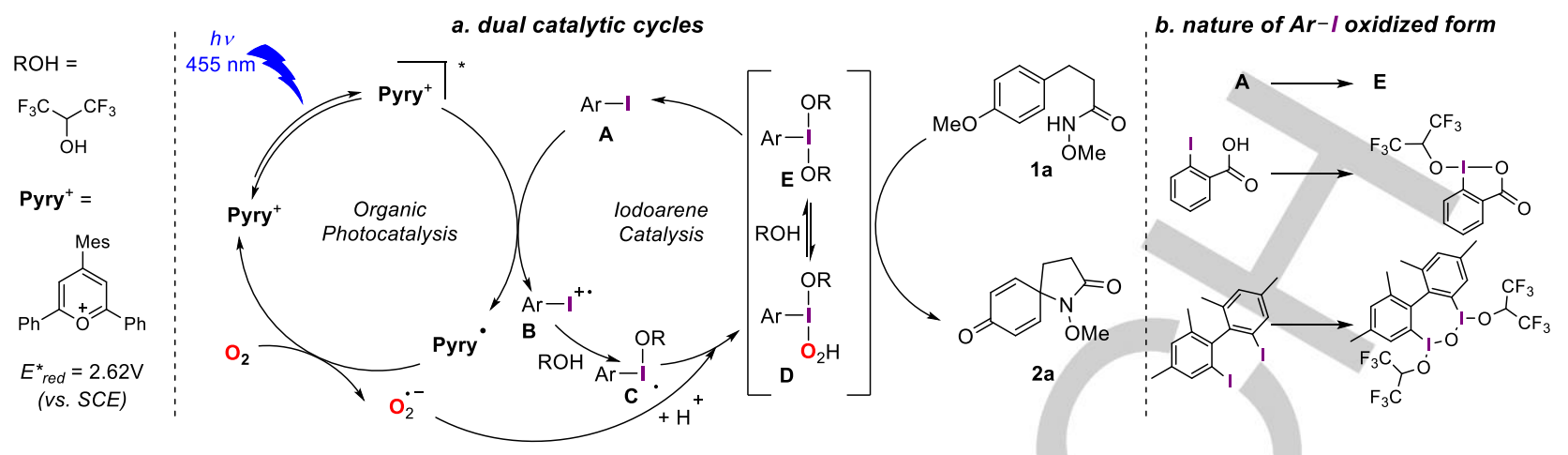

Scheme 5. Mechanistic proposal: (a) dual catalytic cycles and (b) putative structure of the solvolyzed Arl(III) species.

The stability of the can also be further enhanced by The substituents on the aryl group of $\mathbf{A}$, can play a crucial role in the stabilization of the hypervalent iodine(III) reagents generated. From IBA, the formation of a cyclic benziodoxole would occur for both the peroxy- $\lambda^{3}$-iodane $\mathbf{D}^{[54]}$ and HFIP-derived $\mathbf{E}$ (Scheme $5 \mathrm{~b}$ ). For Kita's bis iodoarene catalyst ${ }^{[41]}$ the stabilization would come from the formation of $\mu$-oxo species, here depicted for the fully solvolyzed adduct $\mathbf{E}$.

Using the spiro-cyclization of amides as a model reaction, we have thus demonstrated that aerobic iodoarene catalysis can be enabled by relying on a pyrylium photocatalyst under blue light irradiation. This unprecedented dual organocatalytic system allows the use of low catalytic loading of both catalyst under very mild operating conditions. We are currently pursuing more thorough study of this dual catalyst system to gain a deeper understanding of the reaction pathway by experimental and theoretical methods, with a particular focus on determining the nature of the oxidized iodoarene species. This will allow to expand the range of transformations that can be accomplished using this strategy, including the development of asymmetric reactions.

\section{Acknowledgements}

K.C. thank Prof. S. Quideau (Université de Bordeaux), Dr L. Grimaud (ENS, Paris), Dr I. Ciofini (Chimie ParisTech), Dr N. Hoffmann (Université de Reims) and Pr G. Gasser (Chimie ParisTech) for insightful dicussions. The authors also thank CNRS, ICSN and Chimie ParisTech, for financial support.

This work was supported by a grant from the CNRS (Emergence@INC 2019 program).

\section{Conflict of interest}

The authors declare no conflict of interest.

Keywords: hypervalent iodine $\cdot$ pyrylium $\cdot$ aerobic photoredox reaction $\cdot$ dual organocatalysis

[1] C. Willgerodt, J. Für Prakt. Chem. 1886, 33, 154-160.

[2] V. V. Zhdankin, P. J. Stang, Chem. Rev. 2008, 108, 5299-5358.
[3] M. Brown, U. Farid, T. Wirth, Synlett 2013, 24, 424-431.

[4] A. Yoshimura, V. V. Zhdankin, Chem. Rev. 2016, 116, 3328-3435.

[5] M. Ochiai, Y. Takeuchi, T. Katayama, T. Sueda, K. Miyamoto, J. Am. Chem. Soc. 2005, 127, 12244-12245.

[6] T. Dohi, A. Maruyama, M. Yoshimura, K. Morimoto, H. Tohma, Y. Kita Angew. Chem. Int. Ed. 2005, 44, 6193-6196; Angew. Chem. 2005, 117, 6349-6352.

[7] T. Dohi, Y. Kita, Chem. Commun. 2009, 2073-2085

[8] F. V. Singh, T. Wirth, Chem. - Asian J. 2014, 9, 950-971

[9] X. Li, P. Chen, G. Liu, Beilstein J. Org. Chem. 2018, 14, 1813-1825

[10] F. Berthiol, Synthesis 2015, 47, 587-603.

[11] A. Flores, E. Cots, J. Bergès, K. Muñiz, Adv. Synth. Catal. 2019, 361, 2-25.

[12] T. Fuchigami, T. Fujita, J. Org. Chem. 1994, 59, 7190-7192.

[13] T. Broese, R. Francke, Org. Lett. 2016, 18, 5896-5899.

[14] O. Koleda, T. Broese, J. Noetzel, M. Roemelt, E. Suna, R. Francke, J. Org. Chem. 2017, 82, 11669-11681.

[15] M. Elsherbini, T. Wirth, Chem. - Eur. J. 2018, 24, 13399-13407.

[16] A. F. Roesel, T. Broese, M. Májek, R. Francke, ChemElectroChem 2019, 6, 4229-4237.

[17] R. Francke, Curr. Opin. Electrochem. 2019, 15, 83-88.

[18] M. Elsherbini, B. Winterson, H. Alharbi, A. A. Folgueiras-Amador, C. Génot, T. Wirth, Angew. Chem. Int. Ed. 2019, 58, 9811-9815.

[19] A. Maity, B. L. Frey, N. D. Hoskinson, D. C. Powers, J. Am. Chem Soc. 2020, 142, 4990-4995.

[20] H. G. Roth, N. A. Romero, D. A. Nicewicz, Synlett 2016, 27, 714-723.

[21] P. M. Wood, Biochem. J. 1988, 253, 287-289.

[22] J. Piera, J.-E. Bäckvall, Angew. Chem. Int. Ed. 2008, 47, 3506-3523; Angew. Chem. 2008, 120, 3558-3576.

[23] K. Miyamoto, J. Yamashita, S. Narita, Y. Sakai, K. Hirano, T. Saito, C. Wang, M. Ochiai, M. Uchiyama, Chem. Commun. 2017, 53, 97819784.

[24] A. Maity, S.-M. Hyun, D. C. Powers, Nat. Chem. 2018, 10, 200-204. [25] Wöhler, Liebig, Ann. Pharm. 1832, 3, 249-282.

[26] H. L. J. Bäckström, J. Am. Chem. Soc. 1927, 49, 1460-1472.

[27] S.-M. Hyun, M. Yuan, A. Maity, O. Gutierrez, D. C. Powers, Chem 2019, 5, 2388-2404

[28] A. Maity, S.-M. Hyun, A. K. Wortman, D. C. Powers, Angew. Chem Int. Ed. 2018, 57, 7205-7209.

[29] A. Maity, D. C. Powers, Synlett 2019, 30, 257-262.

[30] J. Lalevée, N. Blanchard, M.-A. Tehfe, M. Peter, F. Morlet-Savary, D. Gigmes, J. P. Fouassier, Polym. Chem. 2011, 2, 1986-1991.

[31] L. Wang, J. Liu, Eur. J. Org. Chem. 2016, 2016, 1813-1824.

[32] C. K. Prier, D. A. Rankic, D. W. C. MacMillan, Chem. Rev. 2013, 113 5322-5363.

[33] S. Fukuzumi, K. Ohkubo, Org. Biomol. Chem. 2014, 12, 6059-6071.

[34] D. A. Nicewicz, T. M. Nguyen, ACS Catal. 2014, 4, 355-360

[35] N. A. Romero, D. A. Nicewicz, Chem. Rev. 2016, 116, 10075-10166.

[36] M. Kawase, T. Kitamura, Y. Kikugawa, J. Org. Chem. 1989, 54, 3394 3403.

[37] Y. Kikugawa, E. Miyazawa, T. Sakamoto, HETEROCYCLES 2003, 59 149.

[38] Y. Amano, S. Nishiyama, Tetrahedron Lett. 2006, 47, 6505-6507.

[39] T. Dohi, A. Maruyama, Y. Minamitsuji, N. Takenaga, Y. Kita, Chem Commun. 2007, 1224-1226.

[40] H. Togo, Y. Suzuki, Y. Ishiwata, HETEROCYCLES 2010, 82, 339.

[41] T. Dohi, N. Takenaga, K. Fukushima, T. Uchiyama, D. Kato, S. Motoo, H. Fujioka, Y. Kita, Chem. Commun. 2010, 46, 7697-7699.

[42] M. A. Miranda, H. Garcia, Chem. Rev. 1994, 94, 1063-1089.

[43] E. Alfonzo, F. S. Alfonso, A. B. Beeler, Org. Lett. 2017, 19, 29892992. 
[44] D. J. Wilger, J.-M. M. Grandjean, T. R. Lammert, D. A. Nicewicz, Nat. Chem. 2014, 6, 720-726.

[45] V. V. Zhdankin, Curr. Org. Synth. 2005, 2, 121-145.

[46] Y. Li, D. P. Hari, M. V. Vita, J. Waser, Angew. Chem. Int. Ed. 2016, 55, 4436-4454; Angew. Chem. 2016, 128, 4512-4531.

[47] D. P. Hari, P. Caramenti, J. Waser, Acc. Chem. Res. 2018, 51, 32123225 .

[48] N. Lucchetti, M. Scalone, S. Fantasia, K. Muñiz, Adv. Synth. Catal. 2016, 358, 2093-2099.

[49] M. Hayyan, M. A. Hashim, I. M. AINashef, Chem. Rev. 2016, 116, 3029-3085.

[50] L. Peilleron, P. Retailleau, K. Cariou, Adv. Synth. Catal. 2019, 361, 5160-5169.

[51] I. Colomer, A. E. R. Chamberlain, M. B. Haughey, T. J. Donohoe, Nat. Rev. Chem. 2017, 1, 0088.

[52] N. Shida, Y. Imada, S. Nagahara, Y. Okada, K. Chiba, Commun. Chem. 2019, 2, 1-8.

[53] M. Ochiai, T. Sueda, K. Miyamoto, P. Kiprof, V. V. Zhdankin, Angew. Chem. Int. Ed. 2006, 45, 8203-8206; Angew. Chem. 2006, 118, 8383-8386.

[54] M. Ochiai, T. Ito, Y. Masaki, M. Shiro, J. Am. Chem. Soc. 1992, 114, 6269-6270. 


\section{Entry for the Table of Contents}

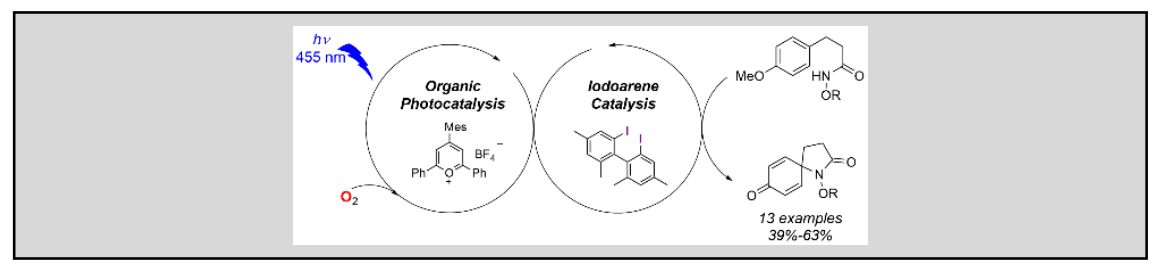

Lighting up iodoarene catalysis: Using the spiro-cyclization of amides as a benchmark reaction, the feasibility of photocatalytic aerobic iodoarene catalysis was demonstrated by relying on a pyrylium photocatalyst under blue light irradiation. This unprecedented dual organocatalytic system allows the use of low catalytic loading of both catalysts under very mild operating conditions.

Institute and researcher Twitter usernames: Dr Kevin Cariou: @CariouK; Chimie ParisTech | PSL: @ChimieParisTech; ICSN: @ICSN_lab. 